of current efforts is not commensurate with the threat we face.

This week, we focus on the issues in depth (see pages 390 and 399), and are providing a freely available, comprehensive collection of previous articles on the topic, not only from Nature but also from all other relevant Nature publications (see www.nature.com/nature/ focus/avianflu/index.html). Nature is also engaged in a collaboration with two other organizations. The journal Foreign Affairs will be publishing a survey of the policy aspects of avian flu and other pandemics in its next issue, to be published in late June. And, with both journals' involvement, the Royal Institution World Science Assembly is organizing a high-level international meeting chaired by Rita Colwell, former director of the US National Science Foundation, that is intended to bridge the gaps between science and policy.

Above all, greater top-level political oversight of the campaign is needed. The time for diplomacy and denial is over. It is time for advocacy and action.

\section{Europe's constitution}

\section{Referenda next week could derail the European project - with negative consequences for science.}

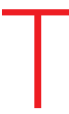

he people of France and the Netherlands will vote next week on whether their respective governments should ratify the proposed European constitution. Despite the traditional roles of both nations as stalwart supporters of greater European unity, their leaders have failed to generate much popular enthusiasm for the document, and both votes are expected to be close.

Research and innovation are critical to Europe's future, but have failed to emerge as an issue in the referendum campaigns. That's a shame, because their successful pursuit could hinge on the outcome of these votes.

The handful of pages in the lengthy constitution document that deal directly with research read blandly, and have inspired little enthusiasm in the scientific community. But there are aspects of the constitution that would herald significant changes in the science policy of the European Union (EU). Previous treaties, for example, have given the EU a remit to support research only as a means of bolstering industrial competitiveness. The constitution would authorize the EU to support science for its own sake.

The constitution would also tie up various loose ends in science policy. The European Research Council, for example, which is being established to support curiosity-driven research, has no legal basis in existing EU statutes, and might be contested by any member state that chose to oppose it. The constitution brings this badly needed new agency safely within the legal remit of the EU.

And the document gives the European Commission powers to remove "legal land fiscal obstacles" to scientific cooperation across borders. It also embraces the right to conduct scientific research "free of constraint", and upholds academic freedom in universities. These components would be steps towards a more open and democratic research system.

Additionally, the constitution "The successful pursuit of research and innovation in Europe could hinge on the outcome of these votes."

is the only instrument on the table that will allow the EU to develop politically, by removing the veto powers of individual states on the Council of Ministers, and by further strengthening the European Parliament. If these reforms succeed, they will help to confer muchneeded legitimacy on EU institutions, and better enable the union to represent its 450 million people on the world stage.

Progress on this has been slow and cumbersome, and the verbosity of the proposed constitution reflects this challenge. Rejecting it will change nothing for scientists who find the EU to be remote and bureaucratic. Accepting it will, at least, open up opportunities for those who want to strengthen European science.

\section{Chemical biology is here}

\section{Nature and its new sibling Nature Chemical Biology reflect an important multidisciplinary trend.}

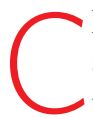
hemical biology is a recent addition to the scientific lexicon, and although its origin involves the use of small molecules to perturb and study biological function, it has recently grown to encompass a wide array of science at the interface between chemistry and biology. Like other multidisciplinary fields, chemical biology thrives because chemists and biologists have unique perspectives and skills that complement each other. For this reason, these collaborative efforts may be able to unravel complex biological problems.

The importance of this growing field can be seen in recent policy initiatives. In 2003, the creation of the US National Institutes of Health Roadmap (http://nihroadmap.nih.gov) led, for example, to the establishment of chemical-genomics screening centres and
PubChem (http://pubchem.ncbi.nlm.nih.gov), a cheminformatics database that is the small-molecule equivalent of PubMed. In addition, several of the recently appointed Howard Hughes Medical Institute investigators (www.hhmi.org/news/032105_list.html) have a significant chemical component to their research.

A year ago, Nature boosted its editorial resources specifically to respond to this trend. And this month our publishers have gone a major step further and launched Nature Chemical Biology (see www.nature.com/nchembio). As with all Nature journals, the new one represents a desire to meet the needs of a community without in any way reducing the commitment of Nature itself to publish high-quality papers in the field. Our aim is that Nature Chemical Biology will rapidly become the home of the strongest research for chemical biologists.

Chemical biology is often the lens that allows the biological community to see what chemists are capable of doing. It is our intention, in both Nature and Nature Chemical Biology, to illuminate the strengths and needs of these two communities and to stimulate new collaborations and scientific insights. 